\title{
Socio-Economic Status of Fishers of Coastal India
}

\author{
Dhande Kranthi Kumar $^{1}$, V. Ramasubramanian ${ }^{2 *}$, M. Krishnan ${ }^{3}$, \\ P.S. Ananthan ${ }^{1}$, A. Vinay ${ }^{1}$ and Ravi Shankar Kumar ${ }^{1}$
}
${ }^{1}$ Fisheries Economics Extension and Statistics Division, ICAR-Central Institute of Fisheries Education, Mumbai, India
${ }^{2}$ Division of Forecasting and Agricultural Systems Modelling, ICAR-Indian Agricultural Statistics Research Institute (IASRI), PUSA, New Delhi, India ${ }^{3}$ Head Education Systems Management, ICAR-National Academy of Agricultural Research Management, Hyderabad, Andhra Pradesh, India
*Corresponding author

\begin{tabular}{|c|c|}
\hline \multicolumn{2}{|r|}{ A B S T R A C T } \\
\hline & \multirow{5}{*}{$\begin{array}{l}\text { The socio-economic status of Indian fishers has been evaluated. In addition, their status } \\
\text { has been compared with an earlier period to see the changes that occurred over time. } \\
\text { Though production has increased over time, growth does not reflect the economic } \\
\text { development of the fishing community and about } 61 \text { per cent of them are living still below } \\
\text { the poverty line. But due to the Government policies and subsidies, their economic } \\
\text { conditions improved during the last one decade. There is an improvement in the fisher's } \\
\text { education, training, diversification of economic activities, employment, savings pattern } \\
\text { and consumption expenditure over time. The increase in the percentage of fishers involved } \\
\text { in subsidiary activity tells that they were not receiving the fruit of increasing fisheries } \\
\text { GDP. The p value of the logistic regression is significant for medium size households, } \\
\text { religion Hindu, land cultivation and age more than } 30 \text { years. MGNREG scheme must be } \\
\text { planned properly and monitored in such a way that the fishers will be benefited to a large } \\
\text { extent during the lean season or ban periods by getting alternative employment. }\end{array}$} \\
\hline Keywords & \\
\hline & \\
\hline Article Info & \\
\hline $\begin{array}{l}\boldsymbol{A c} \\
23 \\
\boldsymbol{A v} \\
10\end{array}$ & \\
\hline
\end{tabular}

\section{Introduction}

India is one of the largest having most diversified livelihood occupations in the world. Most of the people in the country depend on agriculture and its allied sectors including fisheries for their livelihood. But over time, due to industrialisation and urbanization, agriculture is losing its attention and its share in the total GDP has also decreased to 18 per cent in $2015^{(1)}$ from 29 per cent in $1999^{(2)}$. But, one of its allied sectors, the fisheries sector, on the other hand, has become the sunrise sector in the recent years. Its contribution to the national GDP as well as to the agricultural GDP has increased to 1.07 and 5.15 per cent ${ }^{(3)}$ in 2016 respectively from the last few decades.

Fishing is the oldest and most important livelihood option for the inhabitants of the coastal line of the country from time immemorial. This natural resource along with the marine environment provides livelihood 
and employment opportunities for the coastal people and others by way of indirect employment of the coastal population. The total fish production of the country is estimated to be 9.58 Million Tonnes (MT) with a contribution of 6.14 MT from inland sector and 3.44 MT from marine sector $^{(4)}$.Even though production has increased over time, such a growth does not reflect the economic development of the fishing community as still 61 per cent of them are living below the poverty line ${ }^{(5)}$. The fishers' daily income is found to be less ${ }^{(6)}$ and it is depend upon the catch, which is not regular and steady (varies season to season). In addition, inadequate infrastructure facilities and low profitability affect their performance and involvement in other economic activities ${ }^{(7)}$.Daily income of the fishers found to be very less and it is varying as seasonality exists in fishing. Fishing is considered a low income activity because of its social and economic backwardness. Since of the fishers are fully engaged in fishing related activities and their migration to other fields of work is rather difficult. Limited access to land based activities also hinders their economic progress.

\section{Materials and Methods}

The data for the study was taken from the NSSO $68^{\text {th }}(2011-12)^{(8)}$ and $55^{\text {th }}$ (1999$2000)^{(9)}$ rounds which were on 'Household Consumer Expenditure' and 'Employment and Unemployment'. The current socioeconomic status of the fishers has been analysed using NSSO round $\left(68^{\text {th }}\right.$ round, 2011-12). In addition, to assess and compare the changes over time that has happened in their socio-economic status, $55^{\text {th }}$ round (19992000) of NSSO has been taken. Since unit level data for fisher households in each state was very less, in order to have sample sizes, adjacent coastal states and Union Territories (UTs) are categorised under four maritime coasts $^{(10)}$. The four maritime coasts are as follows:

North East Coast (N-E): West Bengal and Odisha

North West Coast (N-W): Gujarat, Maharashtra and Daman \& Diu

South East Coast (S-E): Tamil Nadu, Andhra Pradesh, Pondicherry and Andaman \& Nicobar Islands

South West Coast (S-W): Kerala and Karnataka

It is noted that the coastal state Goa and UT of Lakshadweep Islands have not been considered for the study due to lack of sufficient data points for comparing over time. The results are discussed with the help of Pie diagrams, bar diagrams and tabulations. It is noted that the sample sizes varied between four coasts and also for the same variable in two NSSO rounds. Hence the results are constrained by these limitations.

Logistic regression model ${ }^{(11)}$ has been fitted for the fishers' households of the NSSO $68^{\text {th }}$ round. The null hypothesis assumed for this analysis was that there is no significant effect of the predictors (household size, education, vocational training, age, land cultivated, religion and social group, subsidiary activity and regularly worked) on the dependent variable income. Since income is not available in the data the monthly per capita consumption expenditure (MPCE) has been considered as a proxy for income after eliminating the extreme values (whose consumption expenditure is relatively too less or higher than the other households). The MPCE was multiplied by the household size to arrive at total household income. All the predictors except age (age was taken as such) categorised and coded for fitting the model. 
Since the dependent variable in the logistic regression model is dichotomous in nature so that the income variable was divided into two categories as low and high income groups and were coded as 0 and 1 respectively.

This was done by considering 2nd quartile (Rs. 2733) as the break point. The fisher household income which was less than the break point value considered as low and above it considered as high income groups. The model was fitted in SPSS package ${ }^{(12)}$.

The logistic regression model fitted is

$p(y)=\frac{1}{1+e^{-\left(\beta_{0}+\beta_{1} x_{1}+\beta_{2} x_{2}+\beta_{g} x_{3}+\cdots+\beta_{n} x_{n}+e_{i}\right)}}$

$Y=$ Income groups

$p(y)=$ Probability of occurrence of $\mathrm{y}$

$x_{i}=$ Education, vocational training, age, land cultivated, household size, religion and social group

$\beta_{0}=$ Intercept

$\beta_{i}=$ Slopes

$e_{i}=$ Residuals

The odds ratio can be estimated by using the formula:

Odds ratio $=\frac{p(\text { event } y)}{p(\text { no event } y)}$

$p(y=1)=\frac{1}{1+e^{-\left(\beta_{0}+\sum \beta_{i} x_{i}+\theta_{i}\right)}}$

$p(y=0)=1-p($ event $Y)$

$\Delta$ Odds ratio $=\frac{\text { Odds after a wnit changein predictors }}{\text { Original odds }}$ $=e^{\beta}$
The $\operatorname{Exp}\left(\widehat{\beta}_{2}\right)$ indicates the change in odds ratio of before and after a unit change in the predictors. If the $\operatorname{Exp}\left(\widehat{\beta}_{2}\right)$ value is more than 1 , it says as the predictor increases, the odds of the outcome occurring increases. Conversely if the $\operatorname{Exp}\left(\widehat{\beta}_{i}\right)$ value is less than 1 , it indicates as predictor increases, the odds of the outcome occurring decreases. The $\operatorname{Exp}\left(\widehat{\beta}_{n}\right)$ values say that more the value, more will be the respective variable contribution to the occurrence of dependent variable.

In order to see whether or not there is any significant effect on the number of fishers involved in the subsidiary activity during two time periods (i.e. 2009-10 and 2011-12) due to imposition of restriction on fishing, test for difference of two proportions has been done $^{(13)}$.

Let $\mathrm{P}_{1}$ and $\mathrm{P}_{2}$ be the population proportions in the years 1999-2000 and 2011-12 respectively. The sample proportions are $\mathrm{p}_{1}$ and $\mathrm{p}_{2}$ and are calculated as

$p_{1}=\frac{x_{1}}{n_{1}}$

$p_{2}=\frac{x_{2}}{n_{2}}$

Where, $x_{1}$ and $x_{2}$ are the number of fishers possessing a given attribute during the years 1999-2000 and 2011-12 respectively. Here $n_{1}$ and $n_{2}$ represent the sample sizes that are drawn from the population with proportions $\mathrm{P}_{1}$ and $\mathrm{P}_{2}$ respectively.

Framing the hypotheses:

$\mathrm{H}_{0}$ : $=P_{2} \quad$ (i.e. no difference between the two population proportions)

$\mathrm{H}_{1}: \neq P_{2} \quad$ (i.e.is a difference between the two population proportions) 


\section{Computation of test statistic}

$$
Z=\frac{\left(p_{1}-p_{2}\right)}{\sqrt{\hat{P} \hat{Q}\left(\frac{1}{n_{1}}+\frac{1}{n_{2}}\right)}}
$$

Here $p_{1}$ and $p_{1}$ are the sample proportions for the two samples, $\mathrm{n}_{1}$ and $\mathrm{n}_{2}$ are the sample sizes of the two samples. Also, is an estimate of the population proportion under $\mathrm{H}_{0}$ which is computed by using the formula

$$
\widehat{\mathrm{P}}=\frac{\left(n_{1} p_{1}+n_{2} p_{2}\right)}{\left(n_{1}+n_{2}\right)} \text { and }=1-\widehat{\mathrm{P}}
$$

\section{Decision criteria}

If the $\mathrm{Z}$ calculated value is more than the $\mathrm{Z}$ table value, $\mathrm{H}_{0}$ is rejected and there is a significant difference between the proportions of attributes in the two populations.

\section{Results and Discussion}

The results and discussion are systematically explained under two sections. Under first section, the current socio-economic status and under the second section changes in the socioeconomic status of fishers over time described systematically.

\section{Assessment of current socio-economic status of fishers}

Maximum number of small families was found in $\mathrm{S}-\mathrm{W}$, medium size families found more in $\mathrm{N}-\mathrm{W}$ and large families found more in S-W. According to CMFRI census $2010^{(5)}$, the average family size for the fishers was 4.63 with maximum of 5.45 for Karnataka and a minimum of 3.70 for Andhra Pradesh. Table 1 shows the distribution of fishers' households as per size.
It has been found that all the fishers are belonged to any of the three major religions viz. Hindu, Muslim and Christian. Hindus are a dominant population among the fisher households in all the coasts. The CMFRI census $2010^{(5)}$ showed that 75.47 per cent of fishers were Hindus. No Christian households were found in N-E and N-W coasts as per the data. Muslim fisher households are found in all the coasts but their percentage was very less compared to Hindus but they were found to be more than the Christian fisher households. Figure 1 shows the religion among the fishers in different coasts.

The major social groups' include Scheduled Tribe (ST), Scheduled Caste (SC) and Other Backward Classes (OBC) and those who do not fall under any of the three major groups were considered under others. The Other Backward Class fishers are found to be more in all the coasts except in N-E coast where Scheduled Caste fishers were found more $(68.63 \%)$. There were no Scheduled Caste fishers in N-W coast and no Scheduled Tribe fishers in S-W coast as per the data. Table 2 depicts social groups of fishers in different coasts.

There were 76.06 per cent of the fishers in the coastal states and UTs educated at different levels and it was found higher than the literacy rate of the rural areas of the country where 68.9 per cent were literates ${ }^{(14)}$. The percentage of literate and illiterate fishers in all the four coasts has been shown in figure 2 .

Vocational training is to prepare a person, especially the youth, for the work and make them employable for a range of occupations in various industries and other economic sectors. About 78.5 per cent of the fishers have not undergone any of the vocational training programmes. The fishers who have received informal training (such as hereditary, self-learning, learning in job etc.) were 17.5 
per cent. Only 4 percent of the fishers have received formal training. The comparison of fishers who have received training in each maritime coast has been shown in figure 3 .

The Mahatma Gandhi National Rural Employment Guarantee programme (MGNREG act, 2005) was initiated by the Government of India for the livelihood security of rural households of the country towards realization of the right to work. MGNREGA provided employment for about 37.06 million people of the country during the year $2010-11^{(15)}$. Table 3 depicts the number of fishers benefited through MGNREG scheme.

The subsidiary activity of a person is the additional economic activity in which he/she is engaged relatively for a short period to get additional income other than his/her major economic activity. It was identified that there were only 48 (22.53\%) fishers involved in the subsidiary activity all over the coastal states. Since 83.4 per cent of the fishers were engaged in full time fishing and its related activities, their participation in the subsidiary activities were found to be less ${ }^{(5)}$.It is observed that in N-E coast 43.75 per cent of fishers were involved in subsidiary activities. The percentage of the fishers who were involved in the subsidiary activity in each coast is depicted in figure 4 .

In all the four coasts, almost 50 per cent of the fishers were fully employed throughout the year (i.e. they were engaged in some economic activity).It is often observed that most of the fishers are unemployed for a couple of months (not necessarily in continuous period) which may be due to the lean season and/or ban on fishing during certain period $\left(15^{\text {th }}\right.$ April to $14^{\text {th }}$ June in east coast and $1^{\text {st }}$ June to $31^{\text {st }}$ July in west coast) in the coastal states and UTs. Table 4 shows the employment/unemployment status of fishers. About 94.37 per cent of the fishers have their own land in all four coasts. But only 21.6 per cent of the fishers used their land for the cultivation of crops. Figure 5 shows the land use pattern of fishers. The average monthly consumption expenditure of the fisher's household was estimated by multiply the MPCE with the household size after eliminating the extreme values. The average monthly consumption expenditure of the fishers' households was in the range of Rs. 2800 to Rs. 3800 in the coastal states. The average monthly expenditure of the fishers in each coast has been depicted in figure 6 .

The fisher's savings pattern and accessibility to the credit institutions can be understood from their bank or post office savings accounts. It was observed that, among all the coastal states and UTs, 83.67 per cent of fishers have either bank or post office savings account. It is noted that, if at all a fisher worked in MGNREG, they may be asked to create an account either in bank or post office through which the payment of the wages usually are made. If any member of the household has such accounts, these will also be considered under this. Table 5 shows savings account details of the fishers in each coast.

The union or association is any registered or recognised body whose membership is open to a section of people of common interest and those are engaged in a specific activity. Its main objective is to look after the interests of its members. Out of 213 households surveyed for the fishers, only 93 households were aware of existence of union or association in their locality.

Out of 93 households, 73 households have membership with union or association and 20 households did not have membership with any of the union or association. Table 6 shows the fishers membership with Unions or association in each coast. 
Assessment of socio-economic status of fishers in coastal India over time

It is noted that the sample sizes of both the NSSO rounds were different and the same household was not surveyed over time, hence the findings have to be seen keeping these issues in mind. It is also mentioned here that the variables which were available in both the rounds only have been considered.

Table.1 Percentage of social groups of fishers

\begin{tabular}{|l|r|r|r|r|}
\hline \multicolumn{1}{|c|}{$\begin{array}{c}\text { Household size } \downarrow \text { (size of } \\
\text { family) }\end{array}$} & \multicolumn{4}{c|}{ Maritime Coasts (per cent) } \\
\cline { 2 - 5 } & \multicolumn{1}{c|}{ N-E } & N-W & \multicolumn{1}{c|}{ S-E } & \multicolumn{1}{c|}{ S-W } \\
\hline Small (4) & 21 & 6 & 48 & 23 \\
& $(41.18)$ & $(24)$ & $(57.14)$ & $(43.40)$ \\
\hline Medium (5-8) & 26 & 16 & 31 & 21 \\
& $(50.98)$ & $(64)$ & $(36.90)$ & $(39.62)$ \\
\hline Large (>9) & $4(7.84)$ & 3 & $5(5.95)$ & 9 \\
& & $(12)$ & & 84 \\
\hline Total (n) & 51 & 25 & 84 & 53 \\
\hline
\end{tabular}

Sample size (n) = 213; (N-E: 51, N-W: 25, S-E: 84 and S-W: 53)

Table.2 Percentage of social groups of fishers

\begin{tabular}{|l|r|r|r|r|}
\hline \multirow{2}{*}{ Social group $\downarrow$} & \multicolumn{4}{|c|}{ Maritime Coasts } \\
\cline { 2 - 5 } & N-E & \multicolumn{1}{|c|}{ N-W } & \multicolumn{1}{c|}{ S-E } & \multicolumn{1}{c|}{ S-W } \\
\hline ST & 9.8 & 24.00 & 9.52 & 0 \\
\hline SC & 68.62 & 0 & 9.52 & 1.88 \\
\hline OBC & 1.96 & 72.00 & 59.52 & 96.22 \\
\hline Others & 19.6 & 4.00 & 21.42 & 1.88 \\
\hline Total & 100.00 & 100.00 & 100.00 & 100.00 \\
\hline
\end{tabular}

Sample size (n) = 213; (N-E: 51, N-W: 25, S-E: 84 and S-W: 53)

Table.3 MGNREG beneficiaries

\begin{tabular}{|l|r|r|r|r|}
\hline \multicolumn{1}{|c|}{ Scheme $\downarrow$} & \multicolumn{5}{|c|}{$\begin{array}{c}\text { Number of fisher beneficiaries through } \\
\text { MGNREG in each coast }\end{array}$} \\
\hline & N-E & N-W & \multicolumn{1}{c|}{ S-E } & \multicolumn{1}{c|}{ S-W } \\
\hline Worked & 16 & 1 & 9 & 0 \\
\hline Did not get work & 4 & 1 & 12 & 0 \\
\hline Did not seek work & 5 & 0 & 3 & 2 \\
\hline Total (n) & 25 & 2 & 24 & 2 \\
\hline
\end{tabular}

Sample size (n) = 53; (N-E: 25, N-W: 2, S-E: 24 and S-W: 2) 
Table.4 Employment status of fishers in each coast

\begin{tabular}{|c|c|c|c|c|}
\hline \multirow[b]{2}{*}{ Employment status $\downarrow$} & \multicolumn{4}{|c|}{ Maritime Coasts } \\
\hline & N-E & $\mathbf{N}-\mathbf{W}$ & S-E & S-W \\
\hline Fully employed & $\begin{array}{r}29 \\
(56.86 \%) \\
\end{array}$ & $\begin{array}{r}12 \\
(48 \%) \\
\end{array}$ & $\begin{array}{r}60 \\
(71.43 \%) \\
\end{array}$ & $\begin{array}{r}30 \\
(56.60 \%) \\
\end{array}$ \\
\hline $\begin{array}{l}\text { Unemployed less than three } \\
\text { months }\end{array}$ & $\begin{array}{r}16 \\
(31.37 \%)\end{array}$ & $\begin{array}{r}9 \\
(36 \%)\end{array}$ & $\begin{array}{r}16 \\
19.05 \%)\end{array}$ & $\begin{array}{r}14 \\
(26.42 \%)\end{array}$ \\
\hline $\begin{array}{l}\text { Unemployed more than three } \\
\text { months but less than six } \\
\text { months }\end{array}$ & $\begin{array}{r}6 \\
11.76 \%) \\
\end{array}$ & $\begin{array}{r}4 \\
(16 \%) \\
\end{array}$ & $\begin{array}{r}8 \\
(9.52 \%) \\
\end{array}$ & $\begin{array}{r}9 \\
(16.98 \%) \\
\end{array}$ \\
\hline Total (n) & $\begin{array}{r}51 \\
(100 \%)\end{array}$ & $\begin{array}{r}25 \\
(100 \%)\end{array}$ & $\begin{array}{r}84 \\
(100 \%)\end{array}$ & $\begin{array}{r}53 \\
(100 \%)\end{array}$ \\
\hline
\end{tabular}

Sample size $(\mathrm{n})=213 ;$ (N-E: 51, N-W: 25, S-E: 84 and S-W: 53)

Table.5 Comparison of fishers savings account details

\begin{tabular}{|l|r|r|r|r|}
\hline \multirow{2}{*}{$\begin{array}{c}\text { Bank/Post Office } \\
\text { Account } \downarrow\end{array}$} & \multicolumn{4}{|c|}{ Maritime Coasts } \\
\cline { 2 - 5 } Yes & N-E & N-W & \multicolumn{1}{c|}{ S-E } & \multicolumn{1}{c|}{ S-W } \\
\hline & 31 & 3 & 26 & 22 \\
No & $(96.88 \%)$ & $(100 \%)$ & $(65 \%)$ & $(95.65)$ \\
\hline & 1 & & 14 & 1 \\
Total & $(3.13 \%)$ & 0 & $(35 \%)$ & $(4.35)$ \\
\hline
\end{tabular}

Sample size (n) = 98; (N-E: 32, N-W: 3, S-E: 40, S-W: 23)

Table.6 Member of any union or association in each coast

\begin{tabular}{|l|r|r|r|r|}
\hline \multirow{2}{*}{$\begin{array}{c}\text { Member in } \\
\text { Union } \downarrow\end{array}$} & \multicolumn{4}{|c|}{ Maritime Coasts } \\
\cline { 2 - 5 } & N-E & N-W & \multicolumn{1}{c|}{ S-E } & \multicolumn{1}{c|}{ S-W } \\
\hline Yes & $5(83.33 \%)$ & $2(50 \%)$ & $33(80.48 \%)$ & $33(78.57 \%)$ \\
\hline No & $1(16.66 \%)$ & $2(50 \%)$ & $8(19.51 \%)$ & $9(21.42 \%)$ \\
\hline Total (n) & $6100 \%$ & $4100 \%$ & $41100 \%$ & $42100 \%$ \\
\hline
\end{tabular}

Sample size (n) = 93; (N-E: 6, N-W: 4, S-E: 41, S-W: 42)

Table.7 Comparison of religion groups of fishers over time

\begin{tabular}{|l|r|r|}
\hline \multicolumn{1}{|c|}{ Religion } & 1999-2000 & \multicolumn{1}{c|}{$\mathbf{2 0 1 1 - 1 2}$} \\
\hline Hindu & 84.20 & 83.57 \\
\hline Muslim & 3.16 & 10.80 \\
\hline Christian & 10.92 & 5.63 \\
\hline Others & 1.72 & 0 \\
\hline Total & $100 \%$ & $100 \%$ \\
\hline
\end{tabular}

Sample size $(\mathrm{n})=348(1999-2000)$ and $\mathrm{n}=213(2011-12)$ 
Table.8 Comparison of fishers belonging to different Social groups

\begin{tabular}{|l|r|r|}
\hline \multicolumn{1}{|c|}{ Social group } & $\mathbf{1 9 9 9 - 2 0 0 0}$ & $\mathbf{2 0 1 1 - 1 2}$ \\
\hline Schedule Tribe & 14.66 & 8.92 \\
\hline Schedule Caste & 27.59 & 20.66 \\
\hline Other Backward Classes & 43.39 & 56.34 \\
\hline Others & 14.37 & 14.08 \\
\hline Total $(\mathbf{n})$ & 100.00 & 100.00 \\
\hline
\end{tabular}

Sample size $(\mathrm{n})=348(1999-2000)$ and $\mathrm{n}=213(2011-12)$

Table.9 Comparison of different education levels of fishers

\begin{tabular}{|l|r|r|}
\hline \multicolumn{1}{|c|}{ Level of Education } & $\mathbf{1 9 9 9 - 2 0 0 0}$ & \multicolumn{1}{c|}{$\mathbf{2 0 1 1 - 1 2}$} \\
\hline Illiterates & 50.57 & 23.94 \\
\hline Below primary & 19.54 & 18.78 \\
\hline Primary & 14.66 & 18.78 \\
\hline Middle school & 9.20 & 20.66 \\
\hline Secondary & 5.17 & 10.80 \\
\hline Higher Secondary & 0.86 & 4.69 \\
\hline Diploma & 0.00 & 0.47 \\
\hline Graduate & 0.00 & 1.88 \\
\hline Total & 100 & 100 \\
\hline
\end{tabular}

Sample size $(n)=348(1999-2000)$ and $n=213(2011-12)$

Table.10 Variables in the equation

\begin{tabular}{|l|r|r|r|r|r|r|}
\hline \multicolumn{1}{|c|}{ Variable name } & \multicolumn{1}{c|}{ B } & \multicolumn{1}{c|}{ S.E. } & \multicolumn{1}{c|}{ Wald } & \multicolumn{1}{c|}{ df } & Sig. (p value) & Ex $(\boldsymbol{\beta})$ \\
\hline $\begin{array}{l}\text { House hold size } \\
\text { (Small) }\end{array}$ & & & 19.791 & 2 & 0.000 & \\
\hline $\begin{array}{l}\text { House hold size } \\
\text { (Medium) }\end{array}$ & 1.639 & 0.368 & 19.786 & 1 & 0.000 & 5.148 \\
\hline $\begin{array}{l}\text { House hold size } \\
\text { (Large) }\end{array}$ & 0.851 & 0.589 & 2.090 & 1 & 0.148 & 2.343 \\
\hline Education (Illiterate) & & & 0.630 & 2 & 0.730 & \\
\hline Education (Primary) & 0.318 & 0.458 & 0.483 & 1 & 0.487 & 1.375 \\
\hline $\begin{array}{l}\text { Education (Middle \& } \\
\text { above) }\end{array}$ & 0.070 & 0.481 & 0.021 & 1 & 0.885 & 1.072 \\
\hline Social (Others) & & & 4.500 & 2 & 0.105 & \\
\hline Social (SC \&ST) & -0.814 & 0.577 & 1.994 & 1 & 0.158 & 0.443 \\
\hline Social (OBC) & 0.068 & 0.512 & 0.018 & 1 & 0.894 & 1.070 \\
\hline Religion(Islam) & & & 3.934 & 2 & 0.140 & \\
\hline Religion (Christian) & 0.680 & 0.851 & 0.640 & 1 & 0.424 & 1.975 \\
\hline Religion (Hindu) & 1.158 & 0.599 & 3.731 & 1 & 0.053 & 3.182 \\
\hline Land cultivated (Yes) & 0.810 & 0.423 & 3.661 & 1 & 0.056 & 2.248 \\
\hline $\begin{array}{l}\text { Training received } \\
\text { (Yes) }\end{array}$ & 0.004 & 0.429 & 0.000 & 1 & 0.993 & 1.004 \\
\hline $\begin{array}{l}\text { Subsidiary activity } \\
\text { (Yes) }\end{array}$ & 0.196 & 0.422 & 0.215 & 1 & 0.643 & 1.216 \\
\hline $\begin{array}{l}\text { Regularly worked } \\
\text { (Yes) }\end{array}$ & 0.569 & 0.514 & 1.228 & 1 & 0.268 & 1.767 \\
\hline Age (>30 years) & 1.058 & .419 & 6.384 & 1 & 0.012 & 2.879 \\
\hline Constant & -3.265 & 1.101 & 8.796 & 1 & 0.003 & 0.038 \\
\hline
\end{tabular}


Table.11 Classificatory ability of logistic regression model

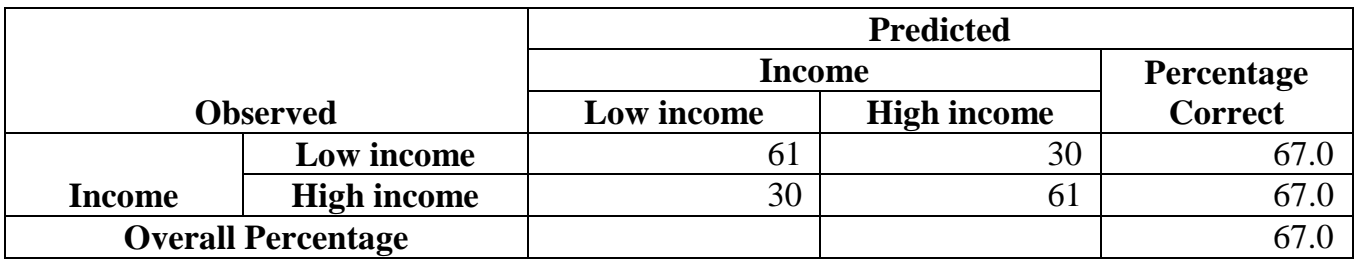

Fig.1 Comparison of religion among fishers

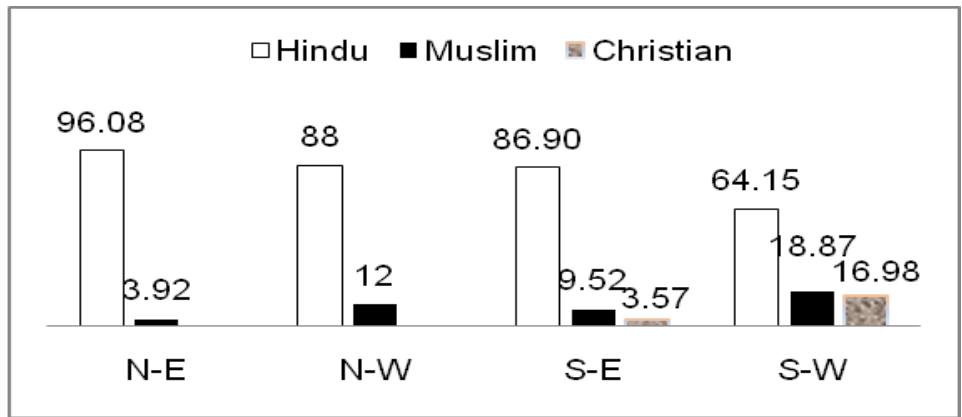

Sample size $(\mathrm{n})=213$; (N-E: 51, N-W: 25, S-E: 84 and S-W: 53)

Fig.2 Literacy rate of fishers

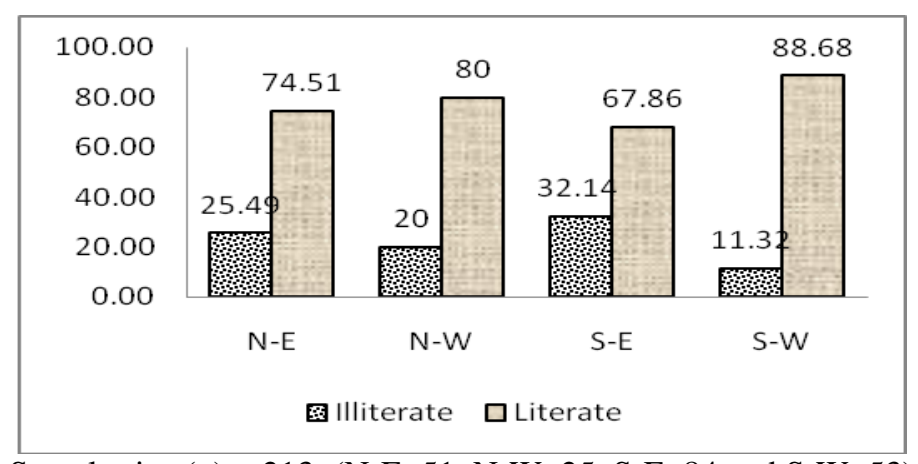

Sample size (n) = 213; (N-E: 51, N-W: 25, S-E: 84 and S-W: 53)

Fig.3 Comparison of training received by fishers

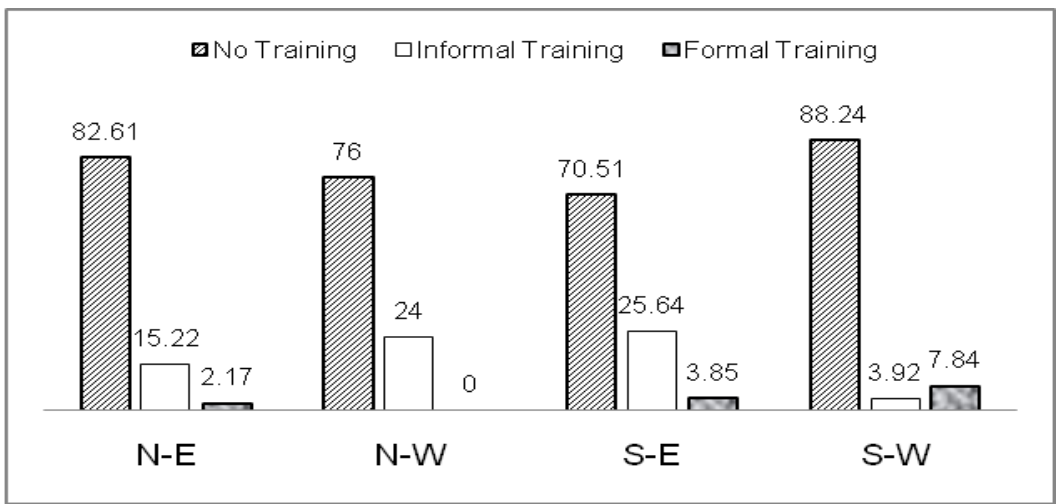

Sample size $(n)=200 ;(N-E: 46, N-W: 25$, S-E: 78 and S-W: 51) 
Fig.4 Comparison of subsidiary activity of fishers

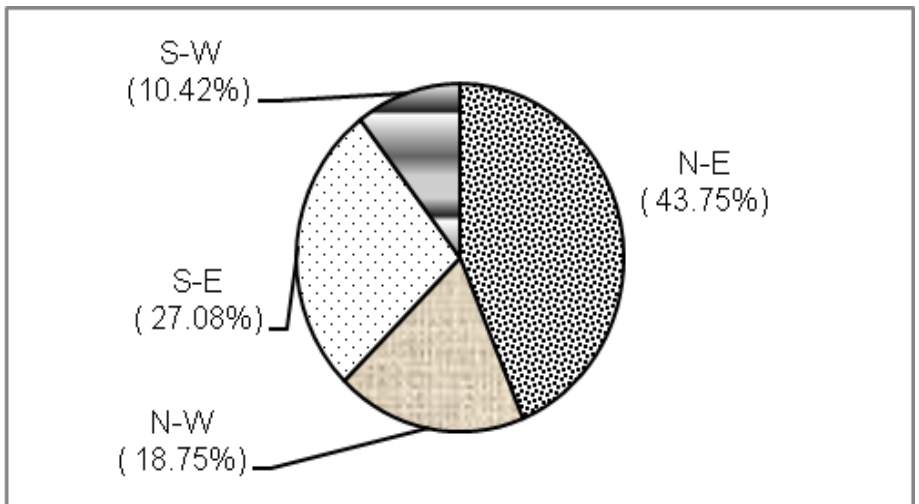

Sample size (n) = 48; (N-E: 21, N-W: 9, S-E: 13, S-W: 5)

Fig.5 Land use pattern of fishers

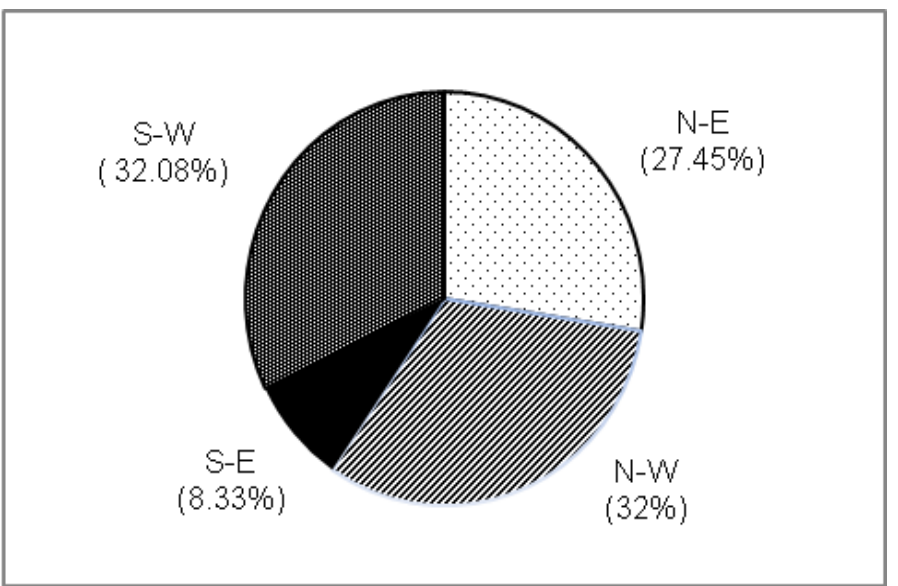

Sample size (n) = 46; (N-E: 14, N-W: 8, S-E: 7, S-W: 17)

Fig.6 Household average consumption expenditure

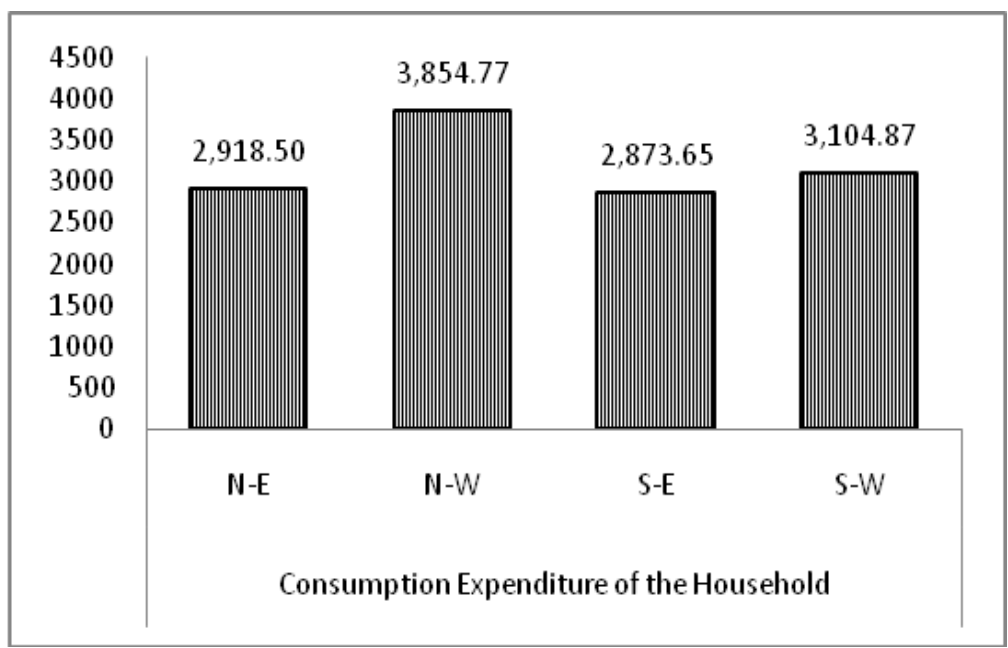

Sample size (n) = 190; (N-E: 42, N-W: 22, S-E: 77, S-W: 49) 
Fig.7 Comparison of having land owned, possessed and cultivated by the fishers

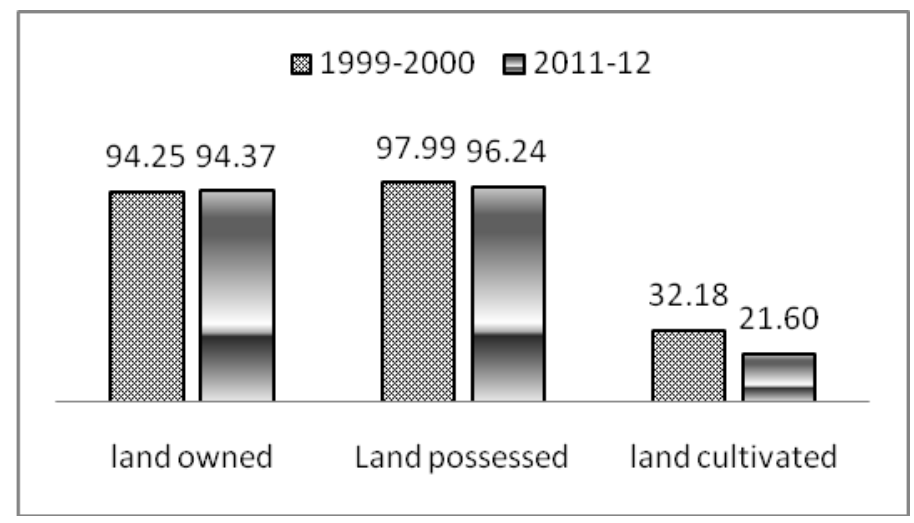

Sample size $(n)=348(1999-2000)$ and $n=213(2011-12)$

The percentage of the fishers belonged to the Hindus found to be more and their per cent was almost same over time. The percentage of the Muslim fishers increased whereas Christian's percentage decreased. Table 7 compares the fishers belonging to different religion groups over time. The Other Backward Class fishers dominating in fishing activity and their proportion seemed to be more in (56.3\%) in 2011-12 than 43.39 per cent in 1999-2000. The fishers belonging to Scheduled Caste and Scheduled Tribes decreased over time. Table 8 compares the status of fishers' social groups over time.

Literacy level among the fishers increased over the period from 49.43 per cent in 1999 2000 to 76.06 per cent in 2011-12. There was a drastic decrease in the per cent of illiterates and increase in the percentage higher education which may be due to the Government of India's provisions for the education in the rural area especially for the people below poverty line. Table 9 depicts the comparison between different levels of education that fishers have undergone over time.

During the year 1999-2000, only 1.44 per cent of the fishers were involved in subsidiary activity. But during the year 2011-12, 22.54 per cent of the fishers were involved in some other economic activity. Due to increase in the fishers' population the per capita available fishing area has decreased. It is also observed that the proportion of owner operators declined over the years due to more capital requirement to have motorized and mechanized fishing units $^{(16)}$. Hence the diversification of economic activities will help them to not fall to debts even during the lean season/ban periods.

In order to see whether there is any significant difference in the fishers engaged in subsidiary activity at two different time periods, the test for equality of two population proportions has been done (discussed in section 2). The $\mathrm{Z}$ calculated value was found to be significant as it was more (8.29) than the table value 1.96 at $5 \%$ level. $\mathrm{H}_{0}$ is rejected, so that there was a significant difference between the fishers who involved in the subsidiary activity in two time periods.

The total number of months when the fishers were without any work increased over time. The fishers who were fully employed were 68.68 per cent in the year 1999-2000 and their per cent reduced to 61.50 in the year 2011-12. The reason could be the imposition of restrictions on fishing and fishing ban periods. Since the fishers were completely dependent on fishing and its related activities as their 
means of livelihoods, most of them are not ready to work in other fields during the lean season or ban periods. Hence their percentage increased over time.

The percentage of the land owned and land possessed (land owned $+/$-leased in or leased out) by the fishers remained same over the years. But use of land for cultivation decreased over the years as it was found that 32.18 percent of the fishers used their land for cultivation during the year 1999-2000 and the same dropped to 21.60 per cent in the year 2011-12. Figure 7 compares the status of land owned, possessed and cultivated fishers over time.

The monthly per capita consumer expenditure (per head consumption expenditure for last 30 days) of the fishers during the year 1999-2000 was Rs.435.74 and it increased to Rs. 619.94 in the year 2011-12. Though the consumption increased over time, they may not buy the same basket of goods as earlier because of the change in the value of money over time. The value of money in real terms (base year) is more than the value of money in current terms. Hence due to fall in the rupee value of money over time, the fishers have to spend even more than before to get the same quantity of goods. In that sense their per head consumption expenditure remained same as there is no much increase in it over time.

The fishers who were members of the work union or association for self-help through the mutual help were found to be reduced over time. It was observed that during the year 1999-2000 there were 81.40 per cent of the fishers who had membership with any union or association. But their percentage slightly reduced to 78.49 in the year 2011-2012.

\section{Logistic regression}

In table 10 the coefficients represent the change in outcome variable (y) with respect to per unit change in the explanatory variables. The Wald test statistic explains the statistical significance of each coefficient ( $\beta$ values) in the model. It has the chi square distribution and it tells whether the $\beta$ coefficients for the predictors are significantly different from zero. If the coefficients are significantly differ from zero, the corresponding predictor contributed for the prediction of outcome. Since the standard errors of all the variables in the model are significantly differ from the zero, we can say that the model predicted the outcome variable well. The $p$ value of medium size household, religion group; Hindu and land cultivated fishers were less than 0.05 hence they are significant. The medium size household was highly significant as it has $\mathrm{p}$ value 0.000 .

The $\operatorname{Exp}(\hat{\beta})$ values of medium size household, Hindus and land cultivated fishers were 5.14, 3.18 and 2.24 respectively. It can be concluded that the medium size fishers have got 5.14 times, fishers belong to Hindu religion have got 3.18 times land cultivated fishers have got2.29 times more income than the other fishers.

The table 11 tells us the predictive power or classificatory ability of the model. The model correctly classified61 households whose income is less than the given reference value and misclassified 30 households as their income was more than the reference value (it correctly classifies $67 \%$ of cases). When the income variable was changed from less income group to more income group (from zero to one), the model correctly classified 61 households, to which the income is more than the reference value and misclassified 30 households as their income is less than the reference value (it correctly classified $67 \%$ of cases). The overall predictability was 67 per cent which was the weighted average of the two cases $(67 \%$ and $67 \%)$. The HosmerLemeshow test explains how well the model 
fit data. The $\mathrm{p}$ value of $\mathrm{H}-\mathrm{L}$ test was found to be 0.43 hence the model is a good fit of the data.

Fishing is the major economic activity of many of the coastal communities. The literacy has improved in all the coastal states and UTs and also over time. But the number of fishers who have studied secondary and above secondary was found to be less. The fishers should be encouraged towards higher education as it forms the base for the development.

Fishers must be encouraged to attend different training programmes to improve their skills in their respective works and it would help them to gain more income. Fishers must also be motivated to take alternative livelihoods which will relieve them from technological shocks and also help them to not fall under debt trap during the lean seasons.

Though the MGNREG is a good start up to remove the unemployment problem in the rural areas, it has to be relooked for its proper implementation particularly in fishing villages where short run unemployment always occurs during the lean season. In order to protect the fishers during lean seasons and ban periods, the Government and the policy makers must relook into the incentives provided to the fishers and care must be taken to see that these measures reached the most backwards in the community.

\section{Acknowledgment}

The authors are grateful to Dr. Gopal Krishna, Director and Vice Chancellor, ICAR-CIFE, Mumbai for encouragement and support during the course of this work. The first author also acknowledges the assistance given by M. Vijaya Krishna, P. Shanthanna and Ubair Nisar for their valuable suggestions while carrying out the study.

\section{References}

1. Economic survey: Key highlights, URL: https:// Www.kpmg.com/IN/en/services /Tax/FlashNews/IES-2014-15.pdf, 2015, Accessed on 06-06-2016.

2. Singh, K., Rural development: principles, policies and management, (Sage publications., New Delhi)1999,pp. 32.

3. National Fisheries Development Board, Department of Animal Husbandry, Dairying and Fisheries. Ministry of Agriculture and Famers Welfare, Government of India. URL: http://nfdb.gov.in/about-indianfisheries.htm. Accessed on 21/07/2016.

4. DAHDF, total fish production: Annual Report 2013-14, Ministry of Agriculture, Government of India. 2014, pp. 1.

5. CMFRI Census, ICAR-Central Marine Fisheries Research Institute, Cochin, Kerala. Indian Council of Agricultural Research, Delhi.2010, pp. 14.

6. Shanmugaraj, T., Upreti, and Ashok, Socio-Economic Status of Fisherfolk Communities in the Gulf of Mannar, Marine Biosphere Reserve, A Survey of Tamil Nadu Forest Department, 1998, pp. 2-4.

7. Sheela, I. and Rao G.S., Social status of Hook and Line Fishermen in Visakhapatnam, Fishery Technology, 2012, pp.204-209.

8. NSSO (2011-2012). National Sample Survey Organisation. $68^{\text {th }}$ round, 'Household Consumer Expenditure' and 'Employment and Unemployment'. Ministry of Statistics and Programme Implementation, Govt of India.

9. NSSO (1999-2000). National Sample Survey Organisation. $55^{\text {th }}$ round, 'Household Consumer Expenditure' and 'Employment and Unemployment'. Ministry of Statistics and Programme Implementation, Govt of India. 
10. Ayyappan S., Sugunan V. V., Jena J.K. and Gopalakrishnan, A.,Handbook of Fisheries and Aquaculture,(Directorate of knowledge management in agriculture, Indian Council of Agricultural Research),2011, pp. 2.

11. Hosmer, D. W. and Lemeshow, S., Applied logistic regression, (New York), 1989, pp. 218.

12. Nie, N.H., Bent, D.H. and Hull, C.H.,. SPSS: Statistical package for the social sciences (New York, McGrawHill), 1970.

13. Biradar, R.S., Course ManualFisheries Statistics,ICAR-Central Institute of
Fisheries Education, Mumbai, 2002, pp. 159-165.

14. Census of India,Rural Urban distribution of population,Ministry of Home Affairs, Govt. of India,(New Delhi),2011, pp. 8.

15. Haque, T., Socio-Economic Impact of Implementation of Mahatma Gandhi National Rural Employment Guarantee Act in India. Social Change, 3 (2011), 445-471.

16. Sathiadhas, R.,Inter-sectoral Disparity and Marginalization in Marine Fisheries in India. Asian Fisheries Science, 2 (2009), 773-786.

\section{How to cite this article:}

Dhande Kranthi Kumar, V. Ramasubramanian, M. Krishnan, P.S. Ananthan, A. Vinay and Ravi Shankar Kumar. 2017. Socio-Economic Status of Fishers of Coastal India. Int.J.Curr.Microbiol.App.Sci. 6(9): 2267-2280. doi: https://doi.org/10.20546/ijcmas.2017.609.278 